\title{
MAASH Technique for Total Hip Arthroplasty: A Capsular Work
}

\author{
Felipe G. Delgado, MD • Albert Broch, MD • Francisco Reina, MD, PhD • \\ Lluís Ximeno, MD, PhD • David Torras, MD • Francesc García, MD • \\ Antoni Salvador, MD
}

Received: 30 December 2012/Accepted: 27 March 2013/Published online: 21 June 2013

(C) The Author(s) 2013. This article is published with open access at Springerlink.com

\begin{abstract}
Background: Dislocation and leg length discrepancy are major complications following total hip arthroplasty (THA). Many surgical approaches for THA have been described, but none suggest a capsular incision that assures good exposure while maintaining adequate capsule integrity in closure. Purposes: Modified anterolateral approach for stable hip (MAASH) is a modification of the classical Hardinge approach, but specifically preserves the anterior iliofemoral lateral ligament and pubofemoral ligament excising the "weak area" of the capsule, in the so called "internervous safe zone" and introducing the "box concept" for the anterior approach to the hip. This is the main difference of the MAASH approach. This technique can be used as a standard for all THA standard models, but we introduce new devices to make it easier. Methods: From November 2007 to May 2012, data were collected for this observational retrospective consecutive case study. We report the results of 100 THA cases corresponding to the development curve of this new concept in THA
\end{abstract}

Level of Evidence: Therapeutic Study Level IV

Work performed at Hospital de Sant Celoni, Sant Celoni, Barcelona, Catalonia, Faculty of medicine. University of Girona, Catalonia, Spain.

Electronic supplementary material The online version of this article (doi:10.1007/s11420-013-9332-1) contains supplementary material, which is available to authorized users.

F. G. Delgado, MD · A. Broch, MD $(\bowtie) \cdot$ L. Ximeno, MD, PhD •

D. Torras, MD · F. García, MD · A. Salvador, MD

Orthopedic and Trauma Department of the Hospital de Sant Celoni,

Av. Hospital, 19, 08470, Sant Celoni, Barcelona, Catalonia, Spain

e-mail: abrochs@gmail.com

F. G. Delgado, MD • A. Broch, MD • A. Salvador, MD

Arthrocat SLP, Group of Orthopedic Surgery and Sports Medicine, Sant Celoni, Spain

F. Reina, MD, PhD

Medicals Sciences Department, NEOMA Group Research, Faculty of Medicine, University of Girona,

Girona, Catalonia, Spain technique. Results: MAASH technique offers to hip surgeons, a reliable and reproducible THA anterolateral technique assuring accurate reconstruction of leg length and a low rate of dislocation. Only one dislocation and six major complications are reported, but most of them occurred at the early stages of technique development. Conclusion: MAASH technique proposes a novel concept on working with the anterior capsule of the hip for the anterolateral approach in total hip arthroplasty, as well as for hemiarthroplasty in the elderly population with high dislocation risk factors. MAASH offers maximal stability and the ability to restore leg length accurately.

Keywords hip arthroplasty · hip approach · anterior hip capsule $\cdot$ THA stability. leg length discrepancy.

hip capsule anatomy

\section{Introduction}

The optimal choice of surgical approach for total hip arthroplasty (THA) in the adult population is still a subject for debate. There is no sufficient data to affirm whether one surgical procedure is better than another [13]. Many approaches for THA are described. The posterior [20], posterior mini-incision [31], lateral transtrochanteric approach [4], direct lateral approach [10], anterolateral approach [29], and anterior approach [27] are among those procedures, but many other modifications have been reported in the literature. Surgeon preference and orthopedic "schools" have influenced the current procedures for THA.

Complications following THA include dislocation, leg length limb discrepancy, deep vein thrombosis (DVT) and infection. The incidence of these major complications is low [6], but for patients with high expectations, any complication can be devastating. Complications also result in problematic economical impact [19] and often result in malpractice litigation.

The modified anterolateral approach for stable hip (MAASH) is a modification of the classical Hardinge approach that we have been developing since November 2007. 

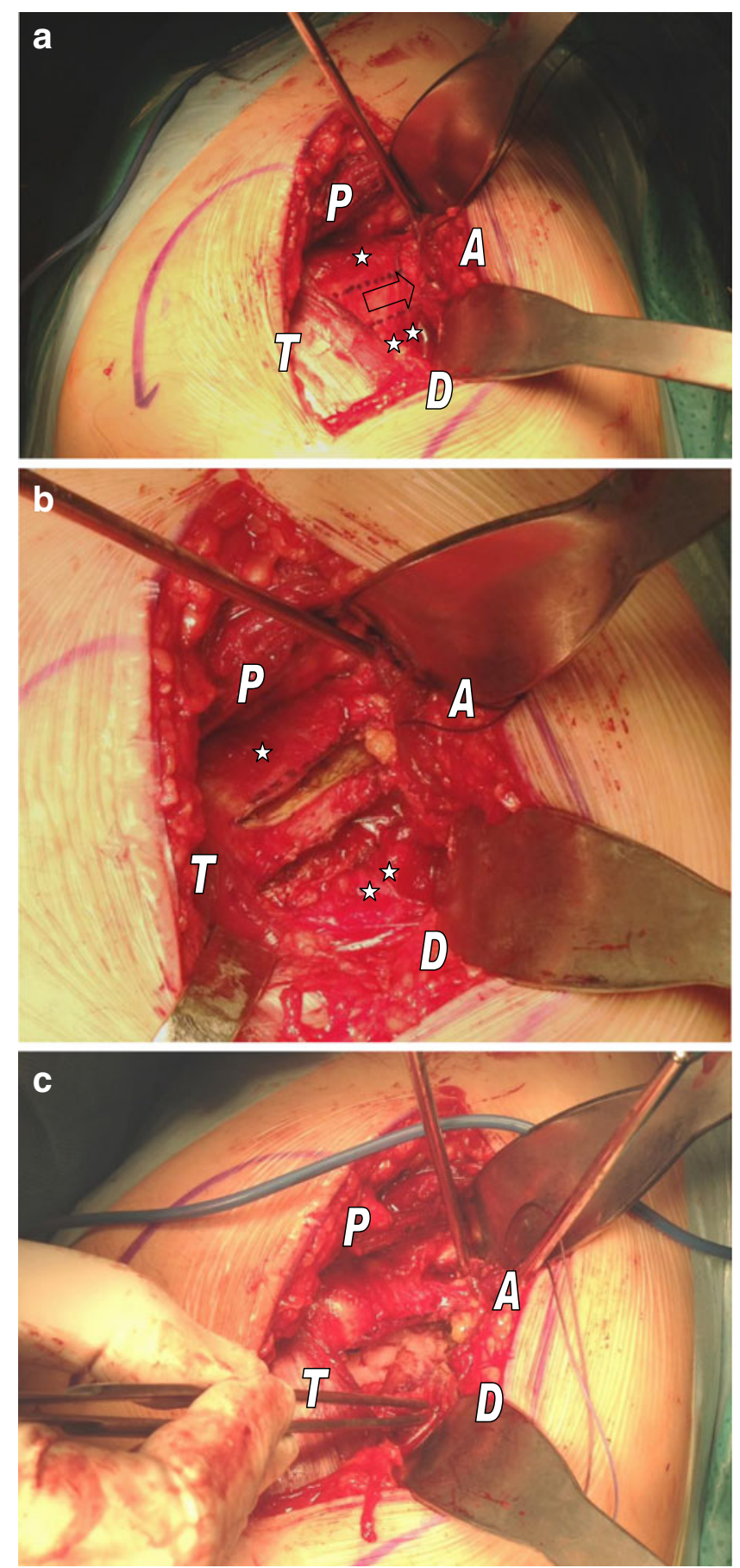

Fig. 1. a Designing intraoperatively the "box concept" in a right hip. Note that vastus lateralis is intact, and from trochanteric line begin a two line draw along femoral neck axis to the acetabular rim. Above the proximal line lateral Iiliofemoral ligament (single asterisk) and below the distal line, we find the pubofemoral ligament (double asterisk). Middle third of the anterior capsule corresponds to the internervous safe zone (arrow). Acetabulum $(A)$, trochanteric line $(T)$, proximal $(P)$, and distal $(D)$. b Incising the capsule through the "box concept." Right hip. Decubitus lateralis position. Above the proximal line (single asterisk) lateral iliofemoral ligament and below the distal line (double asterisk), we find the pubofemoral ligament. Acetabulum $(A)$, trochanteric line $(T)$, proximal $(P)$, and distal $(D)$. c Right hip. Excising the "box concept" tissue from the anterior hip capsulae. Femoral neck and head underneath. Acetabulum $(A)$, trochanteric line $(T)$, proximal $(P)$, and distal $(D)$.
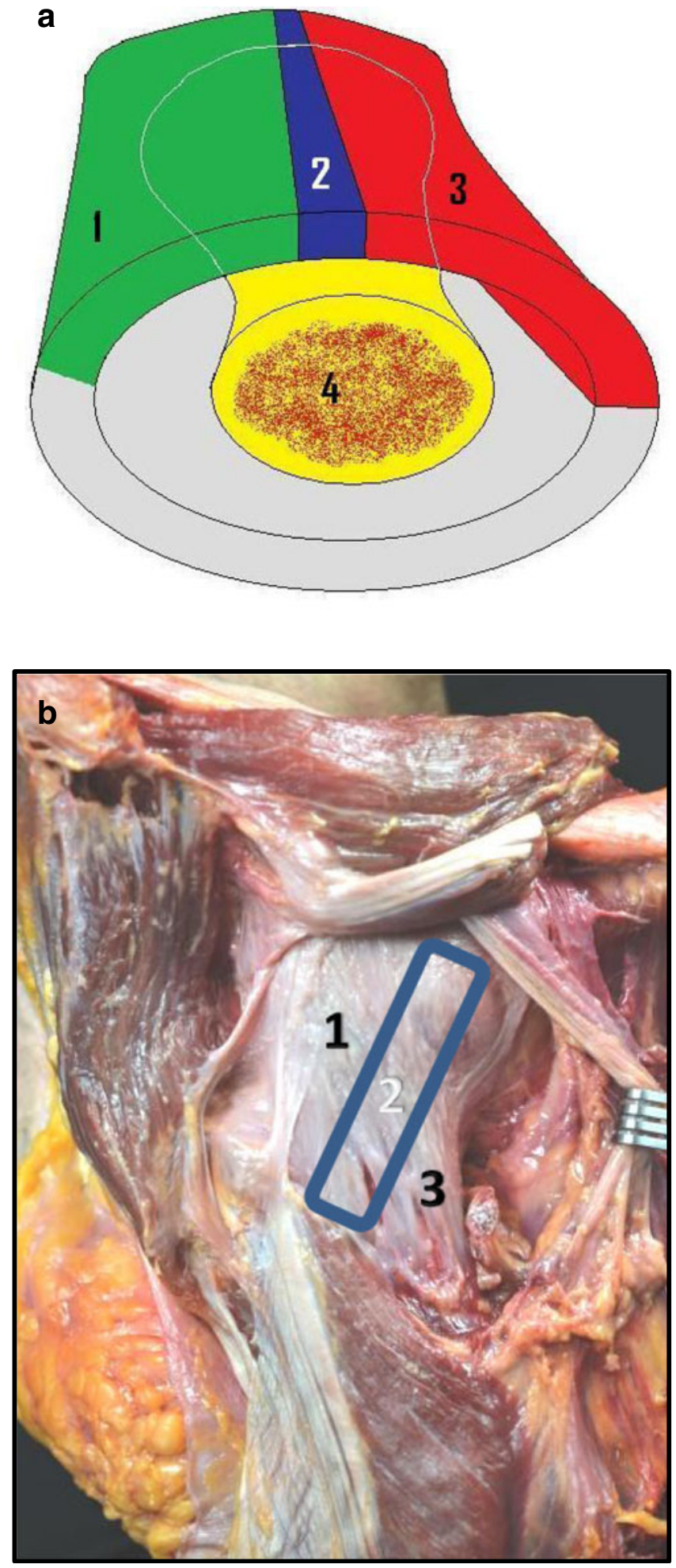

Fig. 2. a The "box concept". Schematic representation of a capsule of the right hip. Lateral decubitus. Note the blue space (2) of the "box" corresponding to the tissue excised. Green (1) Iliofemoral ligament lateral, gray posterior femoral capsule, red (3) pubofemoral ligament, yellow (4) femoral neck and head). b Frozen cadaveric specimen. Right anterior hip capsule. 1 Lateral iliofemoral ligament, 2 "box concept" (blue area), 3 pubofemoral ligament (Courtesy of Dr. Reina, Udg, Cat).

We designed these modifications in order to eliminate the occurrence of dislocation [31], improving our ability to 
restore leg length accurately and optimizing the acetabular cup position. Our aims in this report are primarily to describe a surgical technique that provides specific stability for the primary THA while accurately re-establishing exact leg length. Secondly, we have assessed our learning curve in the development of the technique analyzing surgical timing, accuracy of cup orientation, and complication rates.

\section{Surgical Technique}

MAASH technique is focused on special handling of the anterior hip capsule [17]. A thin rectangular-shaped window of the anterior capsule of the hip is excised, preserving the lateral iliofemoral ligament (LIFL), the majority of the medial iliofemoral ligament (MIFL), and the pubofemoral ligament (PFL) when exposing the joint (Fig. 1a-c). This interval coincides with an internervous "safe zone" of the anterior hip capsule [14], and the technique attempts to preserve the proprioceptive and nociceptive capsular structures. Schematically, one can imagine the hip capsule as a box where the tissue excised is at the anterior wall, and it should not compromise the basic pillars structure because two main ligaments remain intact. We called it "the box concept" (Fig. 2a, b).

MAASH technique is not indicated in those cases where a lengthening of the lower limb is expected such in developmental dysplasia (Crowe III or IV [5]) or for most revision arthroplasties. The main indications for this technique include THA for osteoarthritis, avascular necrosis, childhood diseases resulting in degenerative joint disease but minimal deformity, lesser degree dysplasia (Crowe I or II) [5], and hip fractures.

The patient is placed in the lateral decubitus position. Skin incision is placed along the midline of the greater trochanter in a length of $90 \mathrm{~mm}$ from proximal to distal.

The subcutaneous fat and proximal fascia lata are incised, exposing the gluteus maximus. Separation of the gluteus maximus fibers exposes the gluteus medius and minimus. Gluteus medius is separated from the minimus, and a "C-shaped tenotomy" at the femoral insertion of

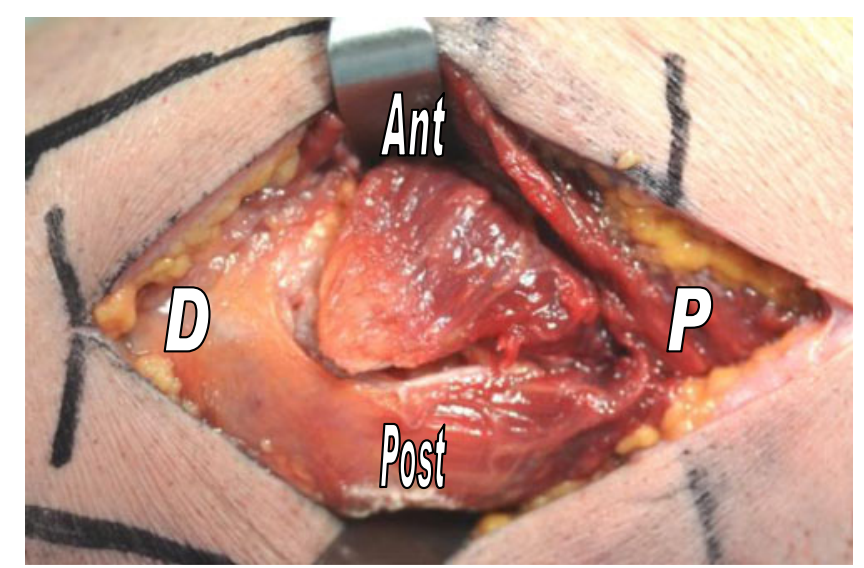

Fig. 3. Left hip. "C" shaped tenotomy for the gluteus minimus. Note the interval between gluteus minimus and gluteus medius. Ant Anterior, Post posterior, $P$ proximal, $D$ distal).

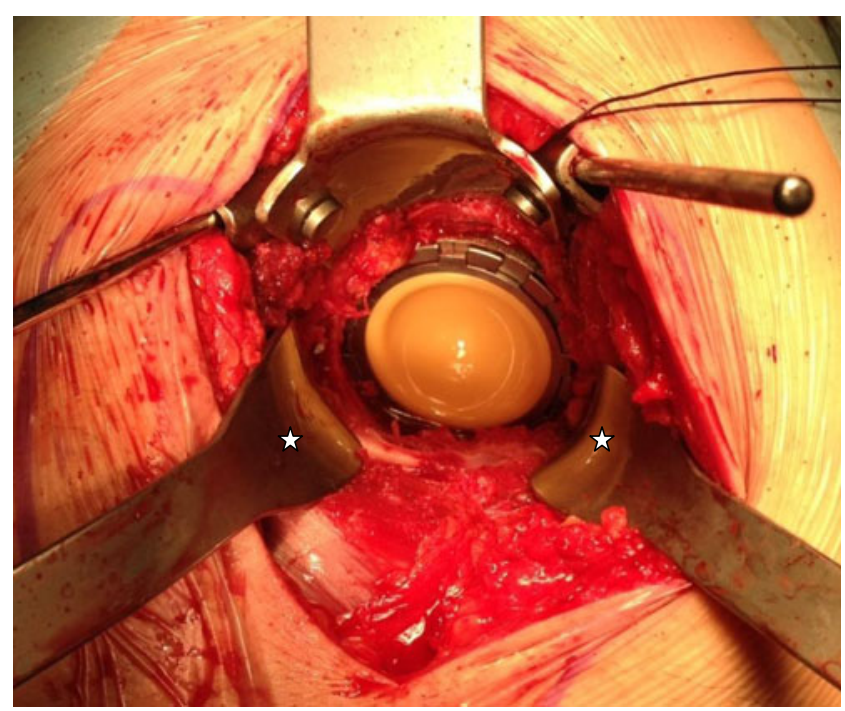

Fig. 4. "66 retractors" (Exactech Inc., Florida, USA). A pair of modified bent Hohmann retractors with a small blunt tip allows obtaining the " $360^{\circ}$ exposure" for the acetabular step when placed at 5 and 7 clockwise (asterisk).

gluteus minimus [2] is performed exposing the anterior hip capsule and the ligament system underneath (Fig. 3). The vastus lateralis tendon is not incised.

Once the anterior hip capsule is exposed, the middle third (subdividing the capsule in thirds) is excised as a rectangle-shaped piece of tissue of $10 \mathrm{~mm}$ along the femoral neck axis, which corresponds to the internervous and weak area of the anterior hip capsule (Fig. 1a-c).

Modified Hohmann retractors (coined "66 retractors", see Fig. 4) are placed under the ligaments on both sides of

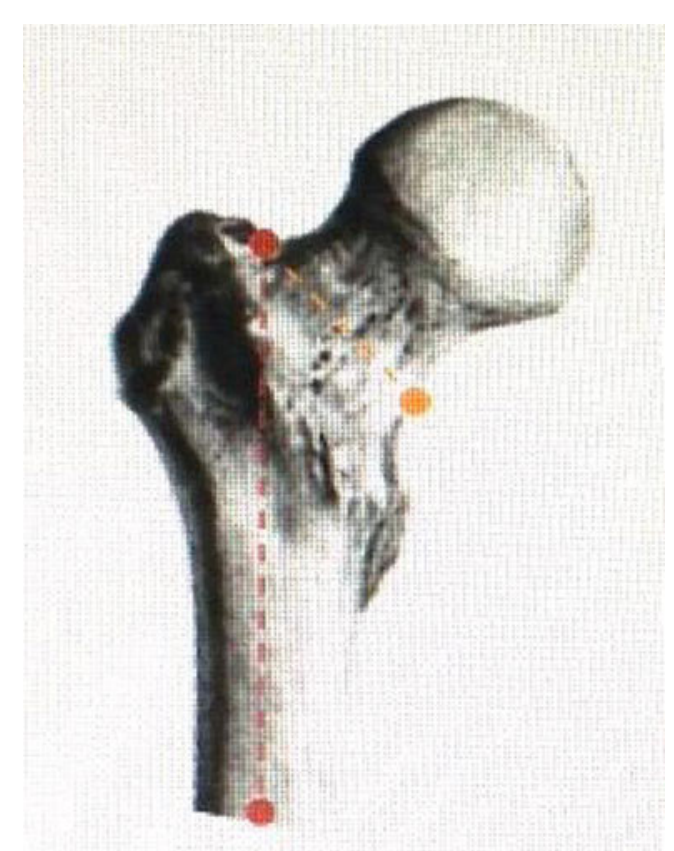

Fig. 5. The 45 rule. From the trochanteric fossa (commonly confound with piriformis fossa [23]), mark a $45^{\circ}$ angle with regard to the femoral shaft axis (red line). This is our neck osteotomy line (yellow line). 


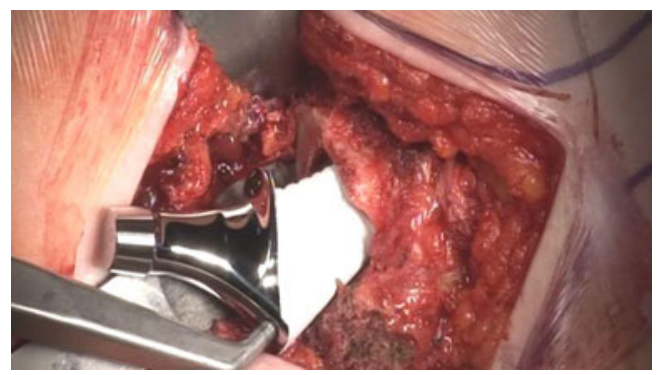

Fig. 6. Right hip. Good exposure of femoral canal. Implanting the stem of noncemented THA.

the femoral neck. Following the " 45 rule" (Fig. 5), from the trochanteric fossae (commonly confound with piriformis fossae [23]), a $45^{\circ}$ angle is marked with regard to the femoral shaft axis and femoral neck osteotomy is performed. It is not mandatory to dislocate the head from the acetabulum to carry out the osteotomy.

Placing a pair of "66 retractors" (Exactech Inc., Florida, USA) and using two Steinman pins placed in superior acetabulum rim, at 5 and 7 o'clock, allow a circumferential exposure of the acetabulum (Fig. 4). If it is difficult to place the retractors, the surgeon should check the femoral neck osteotomy because it maybe too long or not properly angled. Once the acetabular cartilage is removed and the bone is ready to receive the THA cup, we incise the transverse acetabular ligament to widen the access for the cup and then impact the acetabulum cup in place. On average, we advocate for $40^{\circ} \pm 5^{\circ}$ of abduction angle and $0^{\circ}$ to $10^{\circ}$ of anteversion [15]. Screw fixation may be added if necessary.

The "66 retractors" and one "Mueller type" elevator placed at the medial rim of the calcar osteotomy allow exposure of the proximal femur. The femoral canal is prepared according to standard technique (Fig. 6).

Once the definitive femoral component is implanted, the neck length is adjusted, trialing the various neck sizes to reach the right measure using the "equator rule" [28] (see Fig. 7a). The optimal choice of neck length is that which positions the center (equator line) of the prosthetic femoral head trial with traction [21] (Fig. 7b). Our experience suggests that this is exactly the desired length limb and the appropriate height of the femoral head component. We do not recommend actual trial reductions because it would be very difficult to dislocate the trial due to the great stability given by the "box concept."

To assist final reduction, a new tool called "mammoth tusk retractor" (Exactech Inc., Florida, USA; Fig. 8a) has been designed. We place the jaws of this retractor around the femoral neck embracing the prosthesis (Fig. 8b). Then, a strong but smooth force is applied to raise the femur towards the acetabular cup to reduce THA components (Fig. 8c).

a

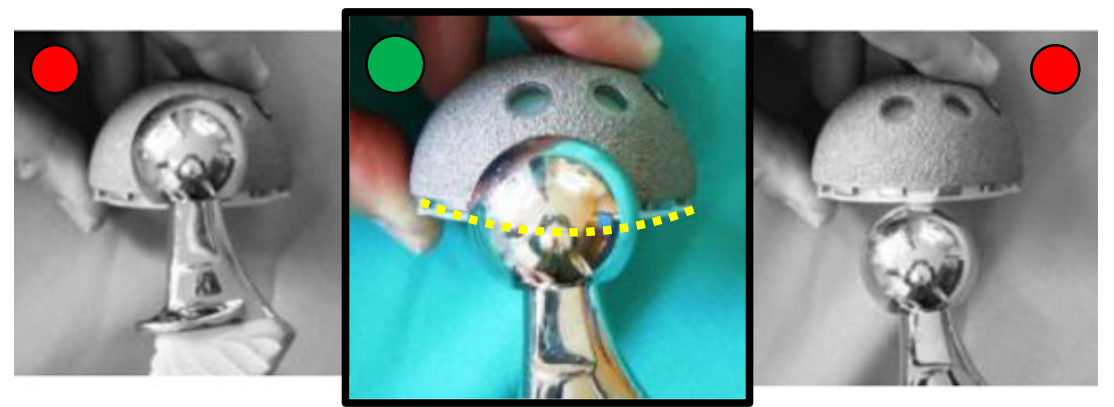

b

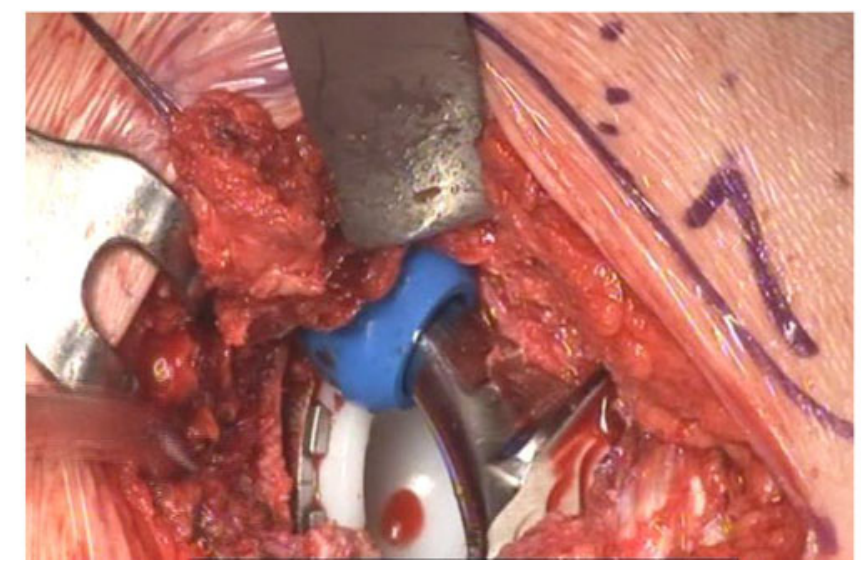

Fig. 7. a The Equator rule [28]. Equator of the femoral head is at the level of the acetabular cup rim only in the middle image. This is the right length of the limb that is assured when surgeon pull the limb to stress the capsular ligaments (schematic view). b "In vivo" view. Note the femoral head trial (blue provisional) in line with the acetabular rim of the cup, which corresponds to the exact length of the definitive head of the prosthesis. 
Obviously, reduction can be achieved without using this tool, but it can be very difficult due to maximal stability of the capsular tissue elements.

The gluteus minimus tendon is sutured $10 \mathrm{~mm}$ distal to its original footprint to restore its function [2] (Fig. 9), avoiding impingement with the major trochanter. The wound is closed as usual, but taking special care to close the fascia properly.

Postoperative rehabilitation plan following MAASH THA is programmed as follows: $6 \mathrm{~h}$ after the procedure, thromboprophylaxis with low-molecular-weight heparin is started and maintained during 30 days. The patient is free to
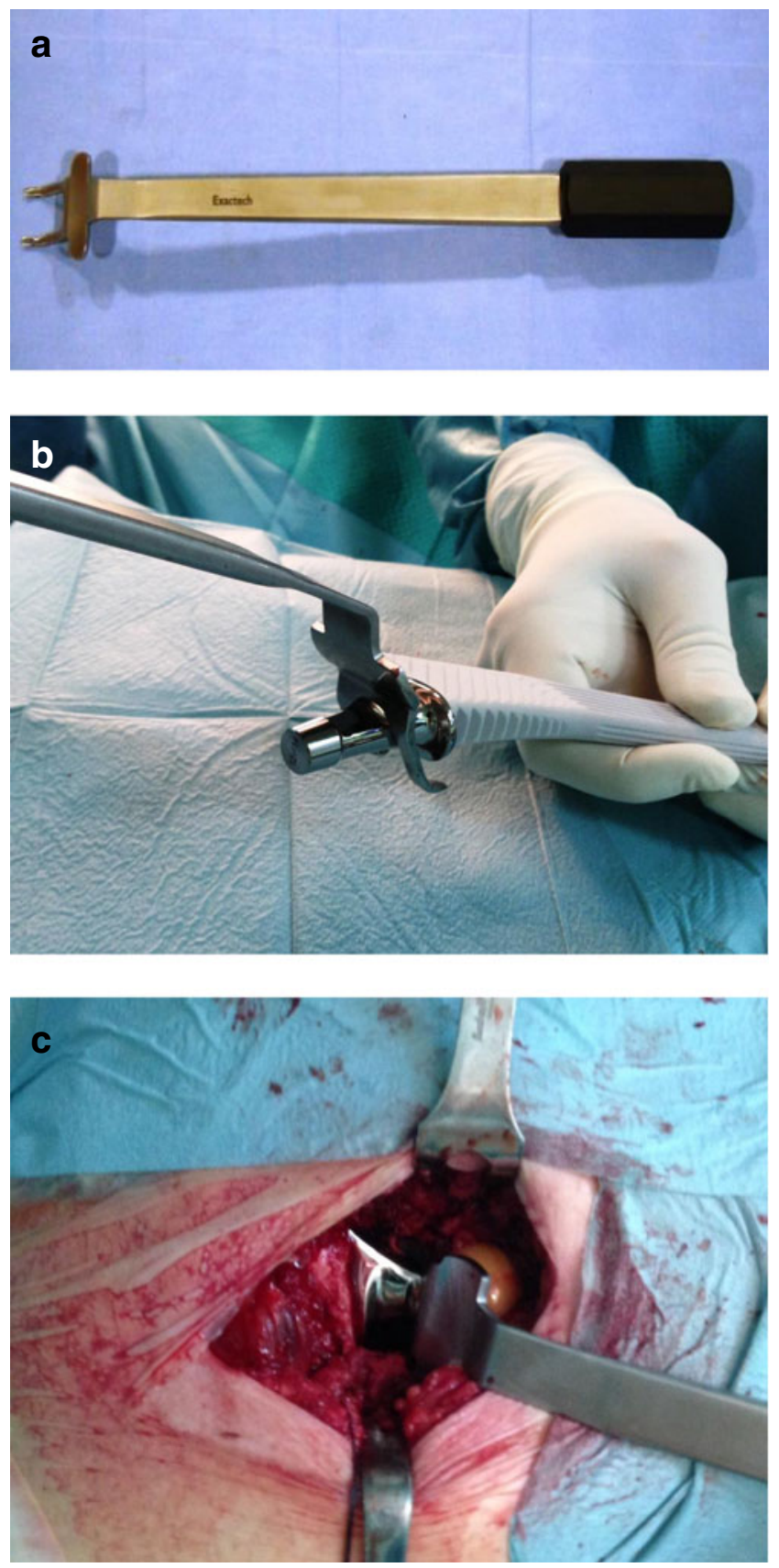

Fig. 8. a "Mammoth tusk retractor" (Exactech Inc., Florida, USA). b Embracing the prosthesis. c Assembling THA components with the Mammoth retractor "in vivo." move the limb. Full weight bearing and walking-assisted program starts $12 \mathrm{~h}$ after the surgery, and it is finished $72 \mathrm{~h}$ with training to climb up and down stairs. We called this period, "THA weekend" because we operate on Friday and the patient is discharged on Monday afternoon. A home physical therapy program for 4 weeks is carried out, and patients can recover full activity, on average at 8 weeks.

\section{Patients and Methods}

From 6th November 2007 to 25th may 2012, we performed at our institution 100 cases of anterior approach and THA. We use the data of these 100 cases to make our statistical analysis.

Of those 100 cases (94 patients and 6 cases double THA), 51 were women, mean age of 70.4 years old (5082 ), and 49 were men, mean age of 63.6 years old (40-82). Twelve cases underwent THA due to hip fracture, and 88 patients were referred from the National Health System for osteoarthritis of the hip. This study is an observational transverse retrospective consecutive case study. Six nonspecific hip surgeons of the orthopedic and traumatology department of our public hospital and the chief of the $\mathrm{Hu}-$ man Anatomy Department at University were involved in this project.

Main indications for this technique are as follows:

- THA for primary hip osteoarthritis

- Secondary hip osteoarthritis (avascular necrosis, some childhood diseases, low degree dysplasia (Crowe I or II) [5])

- Hip fractures.

We developed this technique over a period of 5 years in four stages showing our progress when developing the technique. These stages were defined by the introduction of a "key element," respectively, which we have considered an improvement for MAASH technique:

- Stage I. Starting point: we proceeded with the Hardinge approach as itself (November 2007-November 2008), 28 cases

- Stage II. Development of the "45 rule" (December 2008October 2010), 32 cases

- Stage III. Introduced the "box concept" as a capsular work: MAASH approach itself (November 2010-February 2012), 31 cases

- Stage IV. Mammoth tusk retractor was developed (March 2012-May 2012), nine cases.

For the statistical analysis, chi-square and Fisher's exact tests were used to test for rate differences in different groups (SPSS, IBM v20, evaluation version).

\section{Results}

With experience, the MAASH technique achieved a low dislocation rate with more accurate recreation of the desired leg length. There was one dislocation corresponding to the 34th case in the early second MAASH stage. Regarding leg 
length discrepancy, we observed an improvement along the development curve of this technique. Our results started in a mean value of $4.47 \mathrm{~mm}$ of the first stage to the $2.37 \mathrm{~mm}$ at the fourth one (Fig. 10).

Our results concerning total surgical time (from the skin incision to its closure) have increased because of the development curve, but dramatically diminished when we introduced "Mammoth retractor" at the fourth stage (Fig. 11). Postoperative anemia and blood transfusion in our series conform our first complication (12 cases), and they are directly correlated to surgical time ( $p=0.012$; Fig. 12).

Acetabular cup abduction angle has improved from mean $51.98^{\circ}(28.2-64)$ at first stage to mean 35.53 (24.1-49.6) at the fourth stage. Cup orientation evolved to close $0^{\circ}$ in order to reach our goal of $0-10^{\circ}$ (Figs. 13 and 14).

Complication rate was also improved while the technique has been developed; we have had 21 complications in 20 cases among major and minor complication. From the second stage to the fourth, we have decreased our complications to zero [25] (Fig. 15).

\section{Discussion}

MAASH technique is, in summary, a "capsular work" for anterior THA. Our aims in describing this new concept for the anterior approach were to maintain those main ligamentous structures to allow keeping the intrinsic stability of the capsule and giving the exact leg length to the operated limb, following a primary total hip arthroplasty [9].

We had one case of dislocation (1\%) due to wrong positioning of the cup at $55.3^{\circ}$ of inclination. That case was carried out on the early second stage of MAASH development and was replaced. Risk factors for THA instability are surgical approach, capsular repair, soft tissue tension, component malpositioning, femoral head size, impingement, and surgeon experience [30], and a large economical burden following an unstable THA is about $\$ 74$ million annually [18]. We agree with the results reported in many papers in the literature that converge around $1 \%$ rate in anterior approach THA dislocation [8].

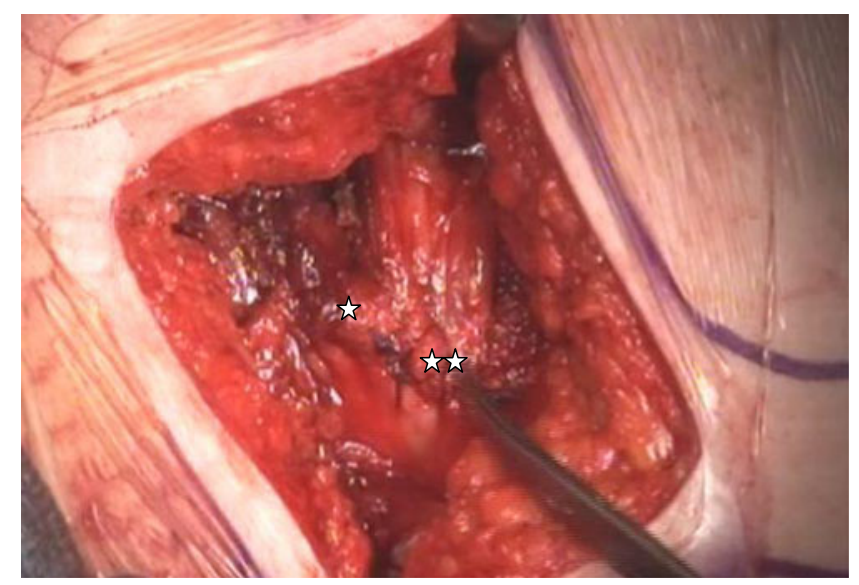

Fig. 9. Long head gluteus minimus reattached $10 \mathrm{~mm}$ distal to its origin (single asterisk original "footprint" gluteus minimus, double asterisk tendon reattached $10 \mathrm{~mm}$ below).

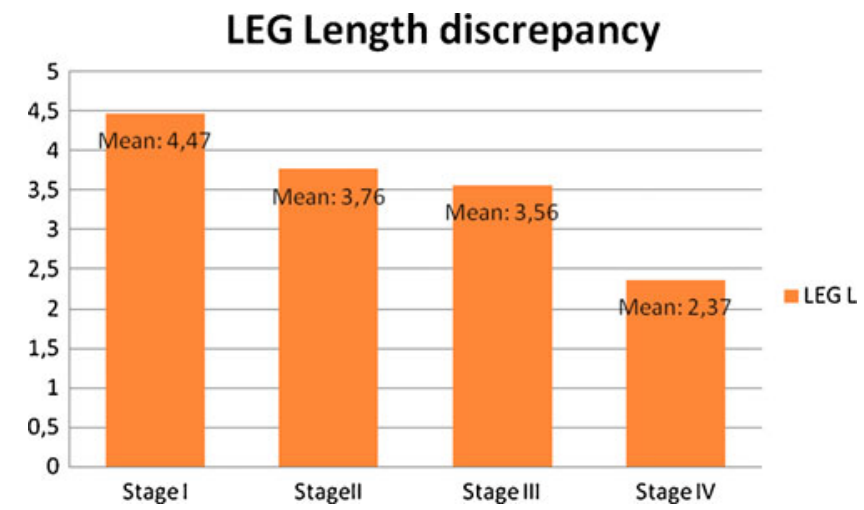

Fig. 10. Leg length discrepancy measured in the postoperative plain X-ray.

Other authors report dislocation rates of $2.18 \%$ for anterolateral approach [24].

MAASH technique does not excise the entire anterior capsule in order to preserve enough ligament elements (LIFL and PFL) keeping the capsule intrinsic stability following "the box concept" (Fig. 2a, b). We do not check softtissue tension to choose the femoral head insert because the tension comes from the capsule ligament remnants. Instead of testing the regular head trials, we follow the equator rule. We assess the prosthetic femoral head provisional implant relative to the superior acetabular rim, and if the center (equator line) of the head trial is in line with the acetabular cup rim [21], this is the right size of the definitive prosthesis head implant (Fig. 7b). We perform the "equator rule" since May 2011 with excellent results of leg length impairment, close to $2 \mathrm{~mm}$ on average. We strongly recommend this maneuver because MAASH technique is extremely stable, and it is very difficult to dislocate when THA components are assembled. Surprisingly from the beginning, our results in terms of leg length discrepancy were good on average. We can accept $<6 \mathrm{~mm}$ of lengthening [11], but we observed that with MAASH technique, the average from the first stage was $4.48 \mathrm{~mm}$ and at the last $2.37 \mathrm{~mm}$, close to the anatomical restoration [12]. By drawing the ischiatic line through both lesser trochanter, we measured the leg limb impairment using the IMPAX ${ }^{\circledR}$ (Agfa-Gevaert Group) computer

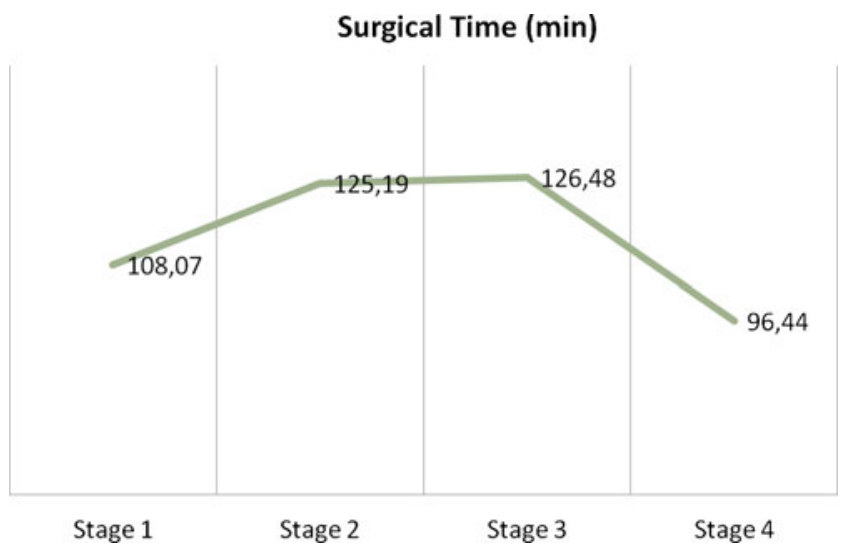

Fig. 11. Time of surgery of development curve MAASH technique. Note the inflexion point on the third and fourth stage. 


\section{Transfusion red cell blood}

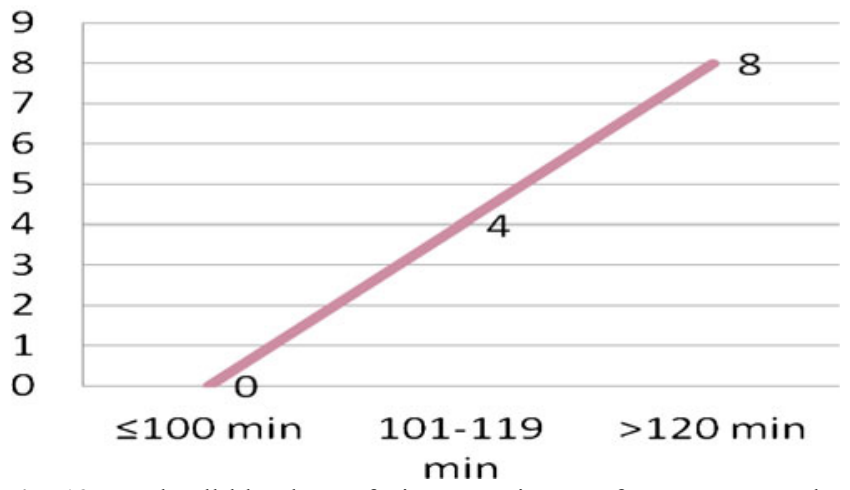

Fig. 12. Red cell blood transfusion vs. minutes of surgery. Note that when surgery surpasses $100 \mathrm{~min}$, the increasing risk for postoperative anemia cases increases exponentially.

program. No X-ray in surgical theatre [11] is needed to assure the right leg length.

There are several modifications of the Hardinge approach $[3,7,16,18,22,26]$, variations of the classical posterior approaches even minimally invasive surgery, and direct anterior approaches [1] for THA, but a specific capsular area excision is described by the MAASH approach. According to Kampa et al. [14], we found that our capsular excision respects the internervous safe zone preserving the proprioceptive and nociceptive structures, and this fact is the main protection against dislocation. Ligaments of the capsule can be shortened, as it occurs in extension plus rotations of the lower limb as a "sandwich effect," but not enlarged. Preserving the maximal anterior capsule ligament but excising the MIFL along the weak area tissue of the anterior hip capsule allows surgeons accessing the hip joint, keeping the THA stability due to capsular and soft tissue balancing and assuring an accurate length of the operated limb. This is "the box concept," which is the main contribution to the THA surgery that MAASH has done. It is not able to perform the "box concept" on the posterior capsule because there does not exist a soft spot and the disposition of the ligament fibers is oblique. We think that this fact should drive in a posterior instability of the capsule.

We described four stages concerning the development of this work. The first and the second stages are related to the

\section{CUP Abduction Angle}

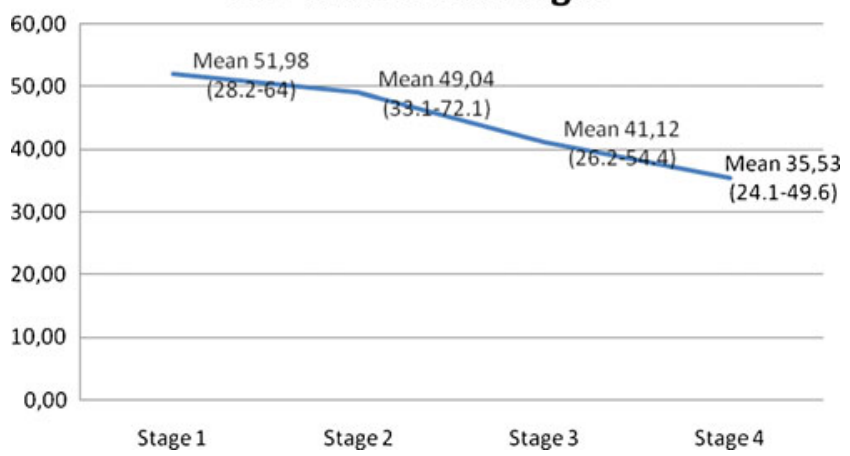

Fig. 13. On average we advocate for $40^{\circ}\left(+-5^{\circ}\right)$ cup abduction angle. Throughout MAASH development stages we have improved our accuracy when placing the prosthesis acetabular component.

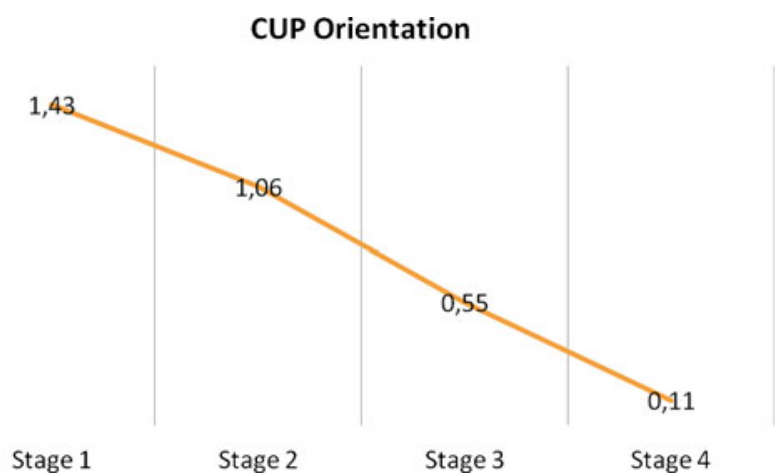

Fig. 14. Acetabular cup orientation. Note that MAASH cases were include in three groups depending on the orientation (group $0^{\circ}$ anteversion angle $=0$, group $0-25^{\circ}$ anteversion angle $=1$, group $>25^{\circ}$ anteversion angle $=2$ ). We improved the accuracy in placing the cup close to $0^{\circ}$ of anteversion.

transition of the classical Hardinge approach to the MAASH. Therefore, the procedure time, complications, and poor accuracy at placing the acetabulum cup mainly occurred at that time. Later on, we improved our results favored by the modification in our THA equipment hardware and the more experience in the approach that we achieved. We tried to place acetabulum cup at $40^{\circ} \pm 5^{\circ}$ of abduction angle and $0-10^{\circ}$ of cup anteversion. Analyzing our results throughout MAASH development, we reduced the abduction angle from $51.9^{\circ}$ to $35.5^{\circ}$ and the anteversion of the cup from more than $25^{\circ}$ to close to $0^{\circ}$ (Figs. 13 and 14). Wearing rates of the acetabular cups seem to be less in $<40^{\circ}$ of abduction angle, and this is important to reduce the reoperation index in THA [28]. From the second stage to the fourth, we have decreased our complication rate to zero [25]. Six major complications were identified: one THA dislocation, one acetabular cup loosening, two deep infection (Enterococcus faecalis and Staphylococcus Epidermidis), one obturator nerve palsy and a deep vein thrombosis. Among the minor complications, 12 cases underwent transfusion of red blood cells due to postoperative anemia, two great trochanter, and one calcar fracture. A series in the literature related to anterior approach for THA reported $16 \%$ of postoperative anemia [1]. It is statistically proved in our study ( $p=$ 0.012 ) when surgery time exceeded $100 \mathrm{~min}$, and it is doubled if surgery goes beyond $120 \mathrm{~min}$ (Fig. 12)

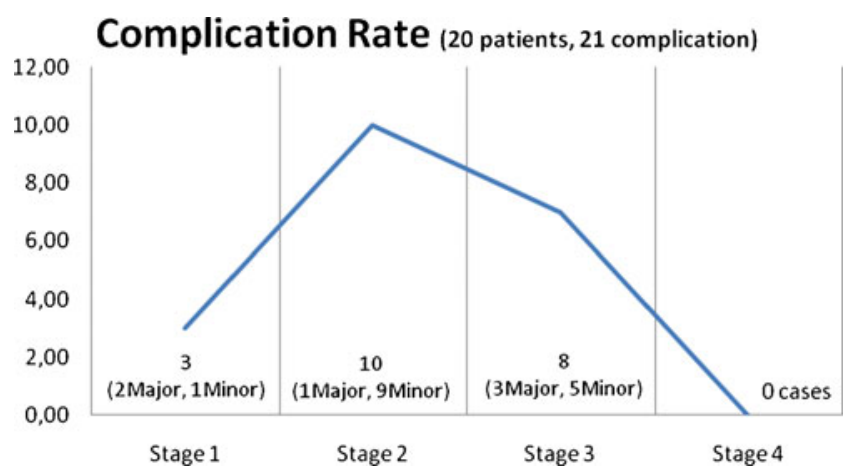

Fig. 15. MAASH development complications curve is presented. Minor and Major complications per stage are reported. 
Although we have modified some retractors and designed the "mammoth tusk retractor" (Exactech Inc., Florida, USA), any hip prosthesis system can be used with MAASH technique but always being conscious that it could be difficult to reduce and assemble the THA components because of the "great stability".

Several lacks and weaknesses in this study can be found. This is an observational retrospective consecutive case study without case control. Instead of this, we compared the results with the current literature. In this study, we present this new anterior approach for the hip, analyzing the stability, leg length impairment, and complications following a THA. We do not report patient satisfaction forms or scores because this would be an issue to treat in another study, which is currently in development.

In conclusion, the MAASH technique is a modified anterior capsular approach for the anterolateral approach in primary total hip arthroplasty. It is also an excellent technique for hemiarthroplasty in the elderly population with high dislocation risk factors. Ligaments of the capsule are incised but not elongated, preserving the anterior hip capsule stability. With the MAASH technique, we achieve maximal stability and leg limb length close to anatomical restoration. We excise the weak area of the anterior hip capsule, preserving the lateral iliofemoral and pubofemoral ligaments and keeping intact the intrinsic stability of the capsule related to the "box concept."

\section{Disclosures}

Conflict of Interest: Albert Broch, MD, is a paid consultant for Exactech Inc. FL, USA, outside the work. Antoni Salvador, MD, is a paid consultant for Exactech, FL, USA, outside the work. Felipe G. Delgado, MD, is a paid consultant for Exactech, FL, USA, outside the work. Francisco Reina, MD, PhD; David Torras, MD; Lluís Ximeno, $\mathrm{MD}, \mathrm{PhD}$; and Francesc García, MD, have declared that they have no conflict of interest.

Human/Animal Rights: All procedures followed were in accordance with the ethical standards of the responsible committee on human experimentation (institutional and national) and with the Helsinki Declaration of 1975, as revised in 2008 (5).

Informed Consent: Informed consent was obtained from all patients for being included in the study.

Required Author Forms Disclosure forms provided by the authors are available with the online version of this article.

Open Access This article is distributed under the terms of the Creative Commons Attribution License which permits any use, distribution, and reproduction in any medium, provided the original author(s) and the source are credited.

\section{References}

1. Beaulé PE. The Anterior Approach for Hip Reconstruction, An Issue of Orthopedic Clinics. 1st ed. Philadephia:Elsevier-WB Saunders;2009.

2. Beck M, Sledge JB, Gautier E, Dora CF, Ganz R. The anatomy and function of the gluteus minimus muscle. J Bone Joint Surg [Br]. 2000;82-B:358-63.
3. Berger RA. Mini-incision totsl hip replacement using an anterolateral approach: technique and results. Orthop Clin N Am. 2004;35:143-151. doi:10.1016/S0030-5898(03)00111-1.

4. Charnley J. Low friction arthroplasty of the hip. Theory and practice. New York: Springer; 1979.

5. Crowe JF, Mani VJ, Ranawat CS. Total hip replacement in congenital dislocation and dysplasia of the hip. J Bone Joint Surg [Am]. 1979;61(1):15-23.

6. Cushner F, Agnelli G, FitzGerald G, Warwick D. Complications and functional outcomes after total hip arthroplasty and total knee arthroplasty: results from the Global Orthopaedic Registry (GLORY). Am J Orthop (Belle Mead NJ). 2010;39(9 Supl):22-8.

7. Dall D. Exposure of the hip by anterior osteotomy of the greater trochanter. J Bone Joint Surg. 1986;68B:382-5.

8. Dudda M, Gueleryuez A, Gautier E, Busato A, Roeder C. Risk factors for early dislocation after total hip arthroplasty: a matched case-control study. J Orthop Surg. 2010;18(2).

9. Elkins JM, Stroud NJ, Rudert MJ, et al. The capsule's contribution to total hip construct stability - a finite element analysis. J Orthop Res. 2011;29:1642-8. doi:10.1002/jor.21435.

10. Hardinge K. The direct lateral approach to the hip. $J$ Bone Joint Surg. 1982;64-B:17-19.

11. Hofmann AA, Bolognesi M, Lahav A, Kurtin S. Minimizing leglength inequality in total hip arthroplasty: use of preoperative templating and an intraoperative x-ray. Am J Orthop (Belle Mead NJ). 2008;37(1):18-23.

12. Huo MH, Gilbert NF, Parvizi J. What's New in Total Hip Arthroplasty. J Bone Joint Surg [Am]. 2007;89(8):18174-85. doi:10.2106/JBJS.G.00509.

13. Jolles M, Bogoch ER. Posterior versus lateral surgical approach for total hip arthroplasty in adults with osteoarthritis. Brigitte. Editorial Group: Cochrane Musculoskeletal Group (2004) (published online: 21 Jan 2009; assessed as up-to-date: 30 Apr 2006). doi: 10.1002/14651858.CD003828.pub3.

14. Kampa RJ, Prasthofer A, Lawrence-Watt DJ, Pattison RM. The internervous safe zone for incision of the capsule hip. A cadaver study. J Bone Joint Surg (Br). 2007;89-B(7):971-976. doi:10.1302/ 0301-620X.89B7.19053.

15. Kummer FJ, Shah S, Iyer S, DiCesare PE. The effect of acetabular cup orientations on limiting hip rotation. J Arthroplasty. 1999;14(4):509-13. doi:10.1016/S0883-5403(99)90110-9.

16. Learmonth ID, Allen PE. The omega lateral approach to the hip. $J$ Bone Joint Surg. 1996;78(B):559-61.

17. Martin HD, Savage A, Braly BA, Palmer IJ, Beall DP, Kelly B. The function of the hip capsular ligaments: a quantitative report. Arthroscopy. 2008;24(2):188-95. doi:10.1016/j.arthro.2007.08.024.

18. Mclauchan J. The Stracathro approach to the hip. J Bone Joint Surg. 1984;66B:30-3.

19. Milton JS. Hip stability in primary total hip arthroplasty using an anatomically sized femoral head. Orthopedics. 2009;32(7):489. doi:10.3928/01477447-20090527-09.

20. Moore AT, Böhlman HR. The classic. Metal hip joint. A case report. By Austin T Moore and Harold R. Clin Orthop Relat Res. 1983;(176):3-6.

21. Pagnano MW, Trousdale RT, Meneghini RM, Hansen AD. Slower recovery after two incision than mini-posterior-incision total hip arthroplasty. J Bone Joint Surg Am. 2009;91(Suppl(Part 1)):50-73. doi:10.2106/JBJS.H.01531.

22. Pai VS. A modified direct lateral approach in total hip arthroplasty. J Orthop Surg (Hong Kong). 2002;10(1):35-9. doi:10.1016/ j.arthro.2007.08.024.

23. Papadakis SA, Shepherd L, Babourda E, Papadakis S. Piriform and trochanteric fossae. A drawing mismatch os a terminology error? A review. Surg Radiol Anat. 2005;27:223-26. doi:10.1007/ s00276-005-0316-9.

24. Patel PD, Potts A, Froimson MI. The dislocation hip arthroplasty: prevention and treatment. J Arthroplasty. 2007;22:86-90.

25. Porucznik MA (2011) "Zero in on zero" to reduce complications. Orthopaedic surgeon leads way to improving care in joint replacement. AAOS now, July 2011.

26. Sánchez PA, Arbeláez WR. Abordaje lateral indirecto modificado en artroplastia de cadera. Rev Col de Ort Tra. 2006;20(3):24-34. 
27. Smith-Petersen MN. Approach to and exposure of the hip joint for mold arthroplasty. J Bone Joint Surg. 1949;31-A:40-46.

28. Udomkiat P, Dorr LD, Wan Z. Cementless hemispheric porouscoated sockets implanted with press-fit technique without screws: average ten-year follow-up. J Bone Joint Surg [Am]. 2002;84(7):1195-1200.
29. Watson-Jones R. Fractures of the neck of the femur. Br J Surg. 1936;23:787-808.

30. Werner BC, Brown TE. Instability after total hip arthroplasty. World J Orthop. 2012;3(8):122-130. doi:10.5312/wjo.v3.i8.122.

31. Wright JM, Crockett HC, Sculco TP. Mini-incision for total hip arthroplasty. Orthopedics (Special Edition). 2001;7(2). 